\title{
VIDEO EDUKASI DAPAT MENINGKATKAN PENGETAHUAN, SIKAP, DAN PERILAKU KELUARGA BERENCANA PASIEN PASCA SALIN
}

\author{
Henri Sulistiyanto $^{1)}$, Suryo Ediyono ${ }^{2)}$ \\ ${ }_{1,2}$ Universitas Sebelas Maret \\ e-mail:henrisulistiyanto2@gmail.com
}

\begin{abstract}
ABSTRAK
Penguatan pelayanan keluarga berencana pasca salin merupakan salah satu upaya percepatan penurunan angka kematian ibu. Target capaian kebutuhan ber-KB yang tidak terpenuhi hanya mencapai 12,1 persen dari target 9,91 persen, serta indikator persentase pemakaian kontrasepsi modern (modern contraceptive prevalence rate/mCPR) hanya sebesar 54,97 persen dari target 61 persen. Kurangnya pengetahuan tentang KB pasca salin menyebabkan masih rendahnya kepesertaan KB pada ibu pasca salin. Penelitian ini bertujuan untuk menguji pengaruh model komunikasi, informasi, dan edukasi berbasis video edukasi terhadap peningkatan pengetahuan, sikap, dan perilaku keluarga berencana pasien pasca salin di RSUD Lawang. Penelitian ini menggunakan metode penelitian quasi experimental dengan rancangan non equivalen control group pretest-posttest design, yang dilakukan pada sampel sejumlah $60 \mathrm{ibu}$ pasca salin. Hasil penelitian menunjukkan ada perubahan yang signifikan pada perilaku KB setelah diberikan video edukasi KB. Rata-rata pengetahuan tentang KB pada kelompok intervensi lebih tinggi (mean $=9,3)$ dibandingkan kelompok kontrol $($ mean $=8,8)$, rata-rata sikap positif terhadap KB pada kelompok intervensi lebih tinggi (mean $=19,4)$ dibandingkan kelompok kontrol $($ mean $=18,4)$, dan ada perbedaan yang signifikan $(p=0,045)$. Sedangkan rata-rata sikap negatif terhadap KB pada kelompok intervensi lebih tinggi $($ mean $=14,6)$ dibandingkan pada kelompok kontrol (mean $=13,27)$ dan terdapat perbedaan yang bermakna $(p=0,037)$. Kesimpulan penelitian ini adalah media video edukasi terbukti mampu meningkatkan pengetahuan, sikap, dan perilaku pasien KB pasca salin.
\end{abstract}

Kata kunci: Komunikasi Informasi Edukasi (KIE); perencanaan keluarga postpartum; video edukasi

\begin{abstract}
Strengthening postpartum family planning services is one of the efforts to accelerate the reduction of maternal mortality rates. The percentage of unmet need for family planning only reaches 12.1 percent of the target of $9.91 \%$ percentage indicator for modern contraceptives (modern contraceptive prevalence rate / $\mathrm{mCPR}$ ) is only 54.97 percent of the target of $61.3 \%$. The Lack of knowledge about postpartum family planning results in low family planning participation. This study aims to examine the effect of educational communication based on a video education to improved knowledge, attitudes, and behavior of postpartum family planning patients in Lawang Hospital. The study used a quasi-experimental research method with a non-equivalent control group pretest-posttest design, were conducted on 60 postpartum mothers. The result showed significant changes in family planning behavior in this study occurred clearly after exposure to the family planning education video. The average knowledge about family planning in the intervention group was higher ( mean $=9.3)$ than the control group $($ mean $=8.8)$ average rate of positive attitude towards family planning in the intervention group was higher (mean $=19.4$ ) than the control group (mean $=18.4)$ and was a significant difference $(p=0.045)$. Meanwhile, the average negative attitude towards family planning in the intervention group was higher (mean = $14.6)$ than the control group (mean $=13.27)$ was also a significant difference $(p=0.037)$. The conclusion is educational video media is proven to be able to improve the knowledge, attitudes, and behavior of postpartum family planning patients.
\end{abstract}

Keywords: Communication Education Information (KIE); postpartum family planning; education video 


\section{PENDAHULUAN}

Keluarga berencana memegang peranan penting terkait Tujuan Pembangunan berkelanjutan (Sustainable Development Goals atau SDGs) (Jurczynska, 2018). Keluarga berencana merupakan investasi yang hemat biaya dalam mencapai SDGs yang memberikan manfaat sosial, ekonomi, dan lingkungan yang luas (Jurczynska, 2018). Wanita masa kini cenderung mempunyai anak lebih sedikit, namun demikian tingkat kesuburan tetap tinggi di beberapa bagian dunia. Tingkat kesuburan global menurun dari 3,2 kelahiran hidup per wanita pada tahun 1990 menjadi 2,5 pada 2019, di Asia Tenggara 2,5 hingga 1,8. Dibandingkan dengan negara lain Indonesia merupakan salah satu negara yang paling sukses dalam melaksanakan program pengendalian jumlah populasi penduduk. Walaupun demikian perkembangan KB di Indonesia belum menggembirakan. Hal ini dapat dilihat dari capaian mCPR 54,97\% dari target 61,3 pada 2019 (BKKBN, 2020).

Penggunaan metode $\mathrm{KB}$ yang tepat, terutama pada saat pasca salin dapat mendukung penurunan Angka Kematian Ibu (AKI). Rumah sakit berperan dalam meningkatkan cakupam mCPR melalui $\mathrm{KB}$ pasca salin dan pasca gugur. Pelayanan Keluarga Berencana Rumah Sakit (PKBRS) cukup efektif dan efisien dalam akselerasi penurunan kematian maternal dan saat sekarang yang utama dilaksanakan adalah program KB pasca salin (KBPS) dan KB pasca gugur (KBPG) (Soetrisno, 2016).

Hasil penelitian menunjukan wanita yang memanfaatkan pelayanan KB-MKJP (mCPR) hanya sebesar 28,7\%. Alasan rendahnya capaian $\mathrm{mPCR}$ salah satunya disebabkan oleh rasa takut dengan cara pemasangan (Pangestika dkk, 2018). Navodani dalam penelitiannya melaporkan dari 382 ibu postpartum $34,4 \%$ enggan mengikuti $\mathrm{KB}$ pasca salin dengan alasan masih akan merencanakanya (Navodani, 2017).

Berdasarkan laporan PKBRS cakupan pelayanan mCPR di RSUD lawang per Januari-September tahun 2020 hanya 4\%. Fenomena ini menunjukan adanya unmeet need pada ibu pasca salin. Dari survei pendahuluan peneliti memperoleh data bahwa sebagian besar dari ibu-ibu pasca salin belum ber KB sampai saat 42 hari setelah persalinan. Dari kunjungan ke poliklinik juga didapatkan kesan kurangnya pengetahuan tentang KB pada pasien-pasien pasca salin di RSUD Lawang. Komunikasi, Informasi, dan Edukasi (KIE) berperan penting dalam upaya meningkatkan partisipasi calon akseptor untuk berKB.

Dalam proses pelaksanaan KIE, terdapat beberapa media yang digunakan, ketepatan pemilihan media yang digunakan akan mempengaruhi keberhasilan dari KIE tersebut. Peralatan audiovisual memungkinkan untuk memproyeksikan gambar hidup, pemutaran kembali suara, dan penayangan visual yang berukuran besar (Smith \& Scot Ransbottom, 2000). Secara khusus, video pendidikan disampaikan melalui situs berbagi video di media social dapat dengan cepat menjangkau khalayak luas (Tuong, 2014).

\section{METODE PENELITIAN}

Penelitian tahap pertama adalah pengembangan modul KIE KB berupa video edukasi dengan menggunakan metode kajian literatur dan konsultasi pada narasumber yang memahami konten promosi $\mathrm{KB}$ di komunitas dari BKKBN, POGI, Kolega konsultan Obstetri Sosial, Bidan Kepala di RSUD Lawang. Animasi dikembangkan oleh pihak ke-3.

Pada tahap ke 2 dari penelitian ini dilakukan uji coba modul KIE video edukasi KB terhadap ibu-ibu pasca salin di RSUD Lawang. Jenis penelitian yang digunakan adalah Quasi Experimental dengan rancangan Non Equivalent Control Group Pretest - Posttest Design. Penelitian dilakukan pada 60 ibu-ibu yang bersalin di RSUD Lawang dan belum ber-KB setelah 42 hari pasca persalinan pada periode penelitian dilakukan. Responden dibagi menjadi dua kelompok, yaitu 30 orang kelompok kontrol dan kelompok intervensi. 


\section{HASIL DAN PEMBAHASAN}

Tabel 3.1 Perbedaan rata-rata pengetahuan, sikap, dan perilaku pre test dan post test pada kelompok intervensi dan kontrol

\begin{tabular}{|c|c|c|c|c|c|}
\hline Kelompok & $\begin{array}{c}\text { Pre test } \\
\text { mean }(\mathrm{SD})\end{array}$ & $\begin{array}{c}\text { Post test } \\
\text { mean }(\mathrm{SD})\end{array}$ & $\begin{array}{l}\text { Post-pretest } \\
\text { Mean (SD) }\end{array}$ & $\begin{array}{c}95 \% \mathrm{CI} \\
\text { selisih mean; } \\
\text { selisih SD }\end{array}$ & P value* \\
\hline \multicolumn{6}{|l|}{ Pengetahuan } \\
\hline Intervensi & $9,3(1,53)$ & $11,8(0,48)$ & $2,5(1,43)$ & $1,965-3,035$ & 0,0000 \\
\hline Kontrol & $8,8(1,8)$ & $9,37(1,4)$ & $0,567(0,73)$ & $0,295-0,838$ & 0,0001 \\
\hline \multicolumn{6}{|l|}{$\begin{array}{l}\text { Sikap positif } \\
\text { terhadap KB }\end{array}$} \\
\hline Intervensi & $19,37(2,17)$ & $21,43(1,41)$ & $2,01(1,21)$ & $1,577-2,556$ & 0,0000 \\
\hline Kontrol & $18,4(2,17)$ & $19,07(1,72)$ & $0,67(0,99)$ & $0,295-1,038$ & 0,0005 \\
\hline \multicolumn{6}{|l|}{$\begin{array}{l}\text { Sikap negatif } \\
\text { terhadap KB }\end{array}$} \\
\hline Intervensi & $14,6(1,13)$ & $13,77(1,38)$ & $-0,83(1,13)$ & $0,522-1,145$ & 0,000 \\
\hline Kontrol & $13,27(1,87)$ & $12,8(2,57)$ & $-0,47(1,22)$ & $0,009-0,924$ & 0,023 \\
\hline \multicolumn{6}{|l|}{$\begin{array}{l}\text { Perilaku } \\
\text { penggunaan } \\
\text { KB** }\end{array}$} \\
\hline Intervensi & $0(0 \%)$ & $13(43,33 \%)$ & $13(43,33 \%)$ & $25,60-61,01$ & 0,012 \\
\hline Kontrol & $0(0 \%)$ & $5(16,67 \%)$ & $5(16,67 \%)$ & $3,00-30,00$ & \\
\hline
\end{tabular}

Tabel 3.2 Perbedaan rata-rata pengetahuan total, sikap total, dan perilaku pre test dan post test antara kedua kelompok

\begin{tabular}{lll}
\hline Kelompok \& parameter & $\begin{array}{c}\text { Pre test } \\
\text { Mean (SD) }\end{array}$ & $\begin{array}{c}\text { Selisih post-pretest } \\
\text { (Mean, SD) }\end{array}$ \\
\hline Pengetahuan tentang KB & & $2,5(1,43)$ \\
\hline Intervensi & $9,3(1,53)$ & $0,56(0,73)$ \\
\hline Kontrol & $8,8(1,80)$ & $1,9(-)$ \\
\hline Selisih I-K & $0.5(-)$ & $1,346-2,521$ \\
\hline 95\% CI & $-1,367-0,367$ & 0,000 \\
\hline p value* & 0,875 & $21,43(1,41)$ \\
\hline Sikap positif terhadap KB & & $19,07(1,72)$ \\
\hline Intervensi & $19,37(2,17)$ & $1,4(-)$ \\
\hline Kontrol & $18,4(2,17)$ & $0,799-2,001$ \\
\hline Selisih I-K & $-0,97(-)$ & 0,000 \\
\hline 95\% CI & $-2,090-0,157$ & \\
\hline p value* & 0,045 & $-0,83(0,83)$ \\
\hline Sikap negatif terhadap KB & & $-0,47(1,22)$ \\
\hline Intervensi & $14,6(1,13)$ & $0,37(-)$ \\
\hline Kontrol & $13,27(1,87)$ & $-0,175-0,908$ \\
\hline Selisih I-K & $-0,97(-)$ & 0,090 \\
\hline 95\% CI & $-2,031-0,098$ & \\
\hline p value* & 0,037 & \\
\hline
\end{tabular}

*data berdistribusi normal, diuji dengan independen t test

Setelah dilakukan intervensi video edukasi, dan dibandingkan persentase jawaban benar pre intervensi dan post intervensi terdapat perbedaan peningkatan pengetahuan yang bermakna pada kelompok intervensi dibandingkan kelompok kontrol.
Peningkatan pengetahuan terjadi pada hampir semua item pengetahuan yaitu pengertian $\mathrm{KB}$, jenis-jenis kontrasepsi seperti kontrasepsi pria, pil/suntik implant, IUD, Tubektomi, dan Vasektomi. Selain itu pengetahuan meningkat tinggi dalam hal efek 
samping KB pil/suntik/IUD dan saat tepat ber-KB. Hal ini menunjukkan bahwa peningkatan pengetahuan ini terjadi karena adanya informasi $\mathrm{KB}$ yang diperoleh dari video edukasi.

Pada kelompok kontrol walaupun ada peningkatan pengetahuan, namun tidak banyak peningkatannya. Peningkatan pengetahuan setelah suatu KIE dengan menggunakan video telah juga dibuktikan oleh banyak peneliti lain. Hal ini selaras dengan beberapa penelitian sebelumnya seperti Armstrong, et al. (2009) yang menyimpulkan bahwa edukasi berbasisvideo merupakan alat yang lebih efektif (Armstrong, Idriss, \& Kim, 2011), khususnya dibandingkan dengan media leaflet dalam transfer pengetahuan dalam suatu konseling atau penyuluhan. Penggunaan media video juga memudahkan seseorang memahami suatu topik, bahkan mengurangi kecemasan, dan mengurangi durasi waktu wawancara (Kakinuma, Nagatani, Otake, Mizuno, \& Nakata, 2011). Menurut Kakinuma, et al. (2011) video edukasi interaktif meningkatkan pemahaman pasien terhadap topik konseling yang berikan.

Video edukasi dapat disimpan, ditransfer, dan dengan mudah diputar sewaktu-waktu, atau memilih memutar frame tertentu, membuat media video edukasi khususnya berbasis digital seperti dalam penelitian ini menjadi efektif, efisien, dan tepat.Temuan dalam penelitian ini maupun fakta-fakta dalam penelitian-penelitian lain yang telah mendahului menunjukkan bahwa KIE konvensional, KIE face-to-face sudah selayaknya mempertimbangkan secara bertahap melakukan subtitusi menuju KIE menggunakan video khususnya video edukasi. Lebih khusus lagi video edukasi berformat digital.

Temuan dalam penelitian ini menunjukkan peningkatan sikap pasca dibandingkan pre intervensi. Sikap positif terbukti mengalami peningkatan yang signifikan, sedangkan sikap negatif mengalami penurunan walaupun tidak terbukti signifikan. Sangat dimungkinkan perubahan sikap yang terjadi merupakan kontribusi dari paparan media video edukasi sebagai KIE, akan tetapi penelitian ini tidak secara khusus menguji apakah perubahan sikap dipengaruhi oleh perubahan pengetahuan. Faktor-faktor yang menentukan perubahan sikap tidak selalu selaras dengan peningkatan pengetahuan. Dalam penelitian ini dimungkinkan perubahan sikap karena perubahan pengetahuan, tetapi tidak dipastikan bahwa perubahan sikap terjadi karena peningkatan pengetahuan yang terjadi di antara responden kelompok internvensi.

Penelitian lain juga menunjukkan bahwa peningkatan pengetahuan tidak selalu diiringi perubahan sikap. Sebuah penelitian menyimpulkan bahwa pengetahuan dan kesadaran tidak selalu diikuti dengan sikap yang positif terhadap penggunaan kontrasepsi KB (Renjhen, Kumar, Pattanshetty, Sagir, \& Samarasinghe, 2010). edukasi. Adanya faktor-faktor lain yang tidak dikendalikan dan tidak bisa diisolasi oleh peneliti seperti adanya paparan informasi dari media lainnya juga merupakan kemungkinan penyebab perubahan persepsi.

Perilaku atau praktek ber KB juga menunjukkan perbedaan dibandingkan dengan skor pra intervensi, terutama pada Ibu yang mendapatkan video edukasi. Walaupun demikian beberapa studi menunjukkan bahwa informasi melalui media video tidak selalu efektif untuk menghasilkan perubahan perilaku. Tuong, et al. 2019, menemukan bahwa intervensi video mempunyai efektifivitas yang bervariasi terhadap perubahan perilaku tergantung dari target perilaku yang dipengaruhi. Intervensi video tampaknya efektif pada: pemeriksaanpayudara-sendiri (sadari), skrining kanker prostate, penggunaan tabir-surya, rawatan mandiri pasien gagal jantung, test HIV, dan penggunaan kondom wanita. Akan tetapi temuan Tuong menyimpulkan bahwa model video memfasilitasi munculnya perilaku baru dan menjadi pertimbangan penting dalam intervensi video yang akan datang (Tuong, Larsen, \& Armstrong, 2019).

Perubahan perilaku ber-KB yang signifikan dalam penelitian ini terjadi jelas setelah paparan video edukasi KB. Walaupun demikian perilaku KB dapat terjadi oleh karena sudah direncanakan oleh responden jauh sebelum intervensi dilakukan atau karena ada faktor lainnya. Sebuah penelitian menunjukkan bahwa alasan paling utama untuk tidak menggunakan kontrasepsi adalah bertentangan dengan kepercayaan agama $(23 \%)$ yang mendorong untuk tidak menggunakan kontrasepsi serta akan 
mengganggu kepuasan seksual, menganggap kontrasepsi menyebabkan kelemahan, sebanyak $10 \%$ menilai bahwa kontrasepsi membuat kegemukan (Renjhen et al., 2010). Temuan lain dari studi ini juga menunjukkan bahwa suami juga berperan terhadap keputusan ibu untuk ber-KB. Artinya bahwa perubahan perilaku ber KB tidak semata-mata pengetahuan, akan tetapi juga perlu difokuskan kepada strategi perubahan nilainilai keyakinan dan pelibatan suami dalam pemeriksaan ante natal maupun konseling pasca persalinan.

Intervensi melalui pemberian video edukasi dapat diberikan pada pasien pasca salin setelah mendapatkan konseling standar di RS. Pemberian intervensi bisa dilakukan berulang sebagai bagian dari upaya untuk mengingatkan pasien ber-KB di bulan-bulan selanjutnya sehingga merupakan kontribusi penting dari obstetric sosial terhadap program KB nasional. Hal ini juga semakin baik jika pemanfatan video dapat diikuti rumah sakit lainnya.

\section{KESIMPULAN}

Media video edukasi terbukti mampu meningkatkan pengetahuan, sikap, dan perilaku pasien KB pasca salin.

\section{SARAN}

Media edukasi dapat direkomendasikan menjadi media edukasi prosedural pada perawtaan post partum di rumah sakit.

\section{REFERENSI}

Al, A. M., Mohammed, S., Ahmed, A., Taisan, A., Mousa, A., \& Ahmad, S.

I. (2018). The effect of a short animated educational video on knowledge among glaucoma patients, 805-810.

Aprilia, E, F. (2015). Pengaruh Media Pembelajaran Audio-visual terhadap Hasil Belajar Siswa Kelas X Pada Mata Pelajaran PAI Di SMA Islam Soerjo Alam Ngajum Malang. Malang.

Armstrong, A. W., Idriss, N. Z., \& Kim, R. H. (2011). Patient Education and Counseling Effects of video-based, online education on behavioral and knowledge outcomes in sunscreen use: A randomized controlled trial. Patient
Education and Counseling, 83(2), 273277. https://doi.org/

10.1016/j.pec.2010.04.033

BKKBN, BPS, \& Kemenkes RI. (2013). Survei Demografi dan Kesehatan Indonesia 2012. Diambil dari http://kesga.kemkes.go.id/images/ pedoman/SDKI 2012-Indonesia.pdf

Darmawan, D. (2011). Inovasi Pendidikan: Pendekatan Praktik Teknologi Multimedia dan Pembelajaran Online. PT. Remaja Rosdakarya., Bandung.

Dirjen Bina Gizi dan KIA. (2013). Rencana Aksi Nasional Pelayanan

Keluarga Berencana 2013 - 2014.

Gerungan, W. (2000). No Title. Bandung: Refika Utama. Gilmore,

B.H (2016). Basics of Applied Behavior Analysis: Part 2: Assessment. Diambil dari https://pro.psychcentral.com/ childtherapist/2016/10/basics-of-appliedbehavior-analysis-part-2-

assessment/?li_source=LI\&li_medium $=$ popular 17

H Hartanto. (2009). Keluarga Berencana dan Kontrasepsi. Jakarta: Pustaka Sinar Harapan.

Handayani, S. (2010). Pelayanan Keluarga Berencana. Yogyakarta: Pustaka Rihama.

Kakinuma, A., Nagatani, H., Otake, H., Mizuno, J., \& Nakata, Y. (2011). The Effects of Short Interactive Animation Video Information on Preanesthetic Anxiety, Knowledge, and Interview Time: A Randomized Controlled Trial, 112(6), 1314-1318. https://doi.org/10.1213/ ANE.0b013e31820f8c18

Kim, Y. M., Bazant, E., \& Storey, J. D. (2006). Smart patient, smart community: improving client participation in family planning consultations through a community education and mass-media program in Indonesia. International Quarterly of Community Health Education, 26(3), 247-270.

Mahmud. (2010). Psikologi Pendidikan. Bandung: PT Mustika Setia. Manuaba, I., Bagus, I., \& Gde, I. (2010). Ilmu Kebidanan, Penyakit Kandungan dan KB untuk Pendidikan Bidan. (2 ed.). 
Jakarta: EGC.

Notoadmodjo, S. (2007). Promosi Kesehatan dan Ilmu Perilaku. Jakarta: Penerbit Rineka Cipta.

NRHM. (2011). Counseling for Postpartum Family Planning and Postpartum IUCD.

Prijatni, I., \& Rahayu, S. (2016). Kesehatan Reproduksi dan Keluarga Berencana.BPPSDM Kesehatan RI.

Renjhen, P., Kumar, A., Pattanshetty, S., Sagir, A., \& Samarasinghe, C. M. (2010). A study on knowledge, attitude and practice of contraception among college students in Sikkim, India, (8), 78-81.

https://doi.org/10.5152/jtgga.2010.03

Saifuddin, A. B. (2010). Buku Panduan Praktis Pelayanan

Kontrasepsi.Jakarta: PT Bina Pustaka Sarwono Prawirohardjo.

Smith, T. L., \& Scot Ransbottom. (2000). Digital Video In Education. Weest Point.

Sulistyawati, A. (2011). Pelayanan Keluarga Berencana. Jakarta: Penerbit Salemba Medika.

Tuong, W., Larsen, E. R., \& Armstrong, A. W. (2019). Videos to influence: a systematic review of effectiveness of video-based education in modifying health behaviors | SpringerLink, 37(2), 10865. https://doi.org/10.1186/1472-6947-10-

Windiana Wahyu Pangestika, Ayun Sriatmi, Sri Winarni. 2018. Pemanfaatan Pelayanan Kb-Mkjp Oleh Pasangan Usia Subur Kelompok Masyarakat Miskin Di Kecamatan Tembalang Kota Semarang Jurnal Kesehatan Masyarakat (e-Journal) Volume 6, Nomor 5

Postpartum family planning: missed opportunities across the continuum of care K T Navodani1, P Fonseka2, C S Goonewardena3 2017. Ceylon Medical Journal 2017; 63: 87-91

William Tuong 1, Elizabeth R Larsen, April W Armstrong 2014 Videos to influence: a systematic review of effectiveness of video-based education in modifying health behaviors. J Behav Med.
WHO. (2019). Family planning / Contraception, (February 2018), 17.

Wea, K. B. (2014) Pendidikan Kesehatan Dengan Media Audiovisual Kabupaten Ngada, pp. 55-61, [serial online], [cited 2018 Desember 1] Kaja Jurczynska, Suzy Sacher \& Scott Moreland Family Planning Can Mean Big Progress for the Sustainable Development Goals-And Here's How https://www.newsecuritybeat.or g/2018/07/family- planning-bigprogress-sustainable-developmentgoals-and-heres/ 